\section{Neoplasia primaria múltiple sincrónica de pulmón}

\section{Sr. Director:}

Paciente varón de 50 años, bebedor importante y fumador activo de dos paquetes/día desde los 19 años. Presenta dolor de perfil pleurítico costal izquierdo de 72 horas de evolución, observándose en la radiografía simple de tórax que se le realiza, una imagen nodular de bordes mal definidos en el lóbulo superior izquierdo.

En el TAC de tórax y abdomen se identifican áreas de enfisema centrolobulillar en ambos lóbulos superiores, con una imagen de infiltrado alveolo-intersticial en el segmento posterior del lóbulo superior izquierdo, de localización periférica y adyacente a la cisura mayor. También se aprecian adenopatías en el espacio paratraqueal derecho e izquierdo, prevasculares, subcarinales traqueobronquiales bilaterales y peribronquiales izquierdas.

Se realiza fibrobroncoscopia donde se observa el árbol izquierdo, ya desde su entrada en bronquio principal, estenosis por compresión extrínseca prácticamente en todo su recorrido, presentando dos zonas, a 1,5 y $3,5 \mathrm{~cm}$ de la carina respectivamente, que infiltran mucosa y donde se toman biopsias y cepillado. En el árbol derecho, se aprecia a la entrada del lóbulo superior, mamelones mucosos con zonas necróticas en su interior de la que también se toman biopsias.

El cepillado de las zonas sospechosas del árbol izquierdo fue compatible con carcinoma de células pequeñas, el diagnóstico fue confirmado en el estudio histológico de la biopsia. Este mismo estudio mostró que los mamelones descritos en el lóbulo superior derecho estaban constituidos por mucosa bronquial con hiperplasia glandular mucosa, metaplasia escamosa inmadura y áreas de carcinoma epidermoide bien diferenciado (Fig. 1).

El paciente fue entonces trasladado al servicio de oncología donde se inició tratamiento quimioterápico.

Las neoplasias primarias múltiples de pulmón (NPMP) son una entidad poco frecuente, con una incidencia que varía del 0,5 al 3,5\% según las series consultadas (1), fundamentalmente en series quirúrgicas y/o necropsias.

Martini y Relamed (2) establecieron en 1975 los criterios diagnósticos de NPMP. Aunque aceptados por la mayoría de los autores, no existe actualmente un modelo unificado para el diagnostico, lo que, unido a la variabilidad de las series estudiadas, podría explicar las diferencias obtenidas en relación con su prevalencia.

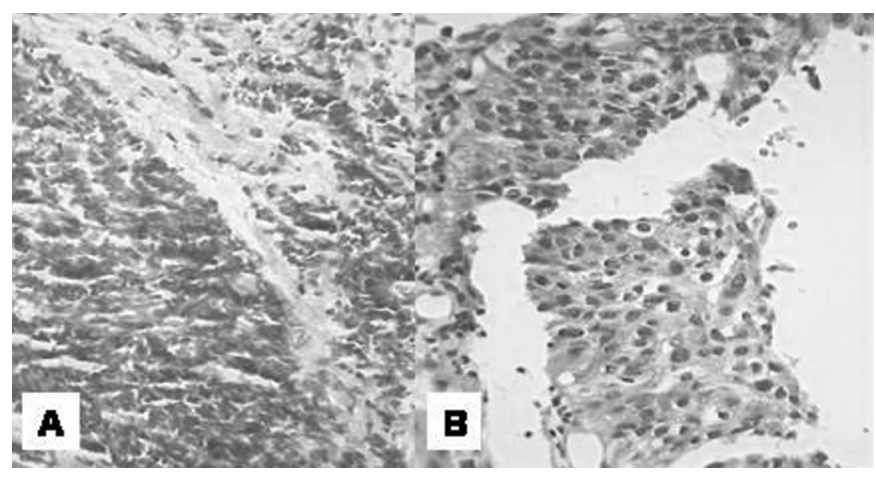

Fig. 1. A. Mucosa bronquial infiltrada por carcinoma de células pequeñas (HE 40x) y B. Celularidad característica de carcinoma epidermoide (HE 40X).

Podemos diferenciar entre tumores sincrónicos, si se presenta simultáneamente, o metacrónicos, si el intervalo de aparición es superior a dos años, siendo este último la forma de presentación más frecuente, generalmente diagnosticados en pacientes intervenidos quirúrgicamente en los que aparece un nuevo infiltrado pulmonar en los controles radiológicos.

La localización más frecuente de las NPMP son los lóbulos superiores, y cuando se presentan de forma sincrónica, suelen hacerlo en un mismo pulmón.

Recientemente, la organización mundial de la salud (3) ha incluido en la clasificación de los tumores pulmonares el carcinoma de células pequeñas combinado, que se define por la asociación en una misma lesión de áreas de carcinoma de células pequeñas con áreas de carcinoma de células no pequeñas, fundamentalmente adenocarcinoma y carcinoma de células escamosas, y en menor medida, carcinoma de células grandes. Estos aspectos abren el debate sobre la vigencia de las clasificaciones de las NPMP, que sin duda será necesario afrontar en los próximos años.

La presencia de tumores histológicamente diferentes en pulmones distintos facilitó el diagnostico de NPMP en nuestro caso, no obstante, este diagnostico no es sencillo. Creemos que fundamentalmente los tumores localizados en un mismo lóbulo o diferentes lóbulos de idéntica histología, presentan grandes problemas a la hora de establecer si se trata de tumores primitivos simples que se extienden por vecindad, metástasis intrapulmonares o NPMP. 
La asociación histológica más frecuente, tanto en tumores sincrónicos como en metacrónicos es la de carcinoma epidermoide-carcinoma epidermoide, seguida de carcinoma epidermoide-carcinoma de células pequeñas y carcinoma epidermoide-adenocarcinoma.

En la mayoría de los casos encontramos la asociación de más de un estímulo oncogénico mantenidos en el tiempo, siendo el principal de todos, el tabaco. Abbey Smith estableció una media de consumo tabáquico de 41 cigarrillos día en los pacientes con NPMP, no encontrando ningún caso de paciente no fumador (4). En nuestro caso se trataba de un paciente joven (50 años) fumador de 62 paquetes/año sin que se pudieran identificar claramente otro estímulos oncogénicos de exposición continuada. Estos hechos justifican la necesidad de un examen completo de todo el árbol bronquial en el estudio endoscópico (5). En nuestro caso contábamos con un fibrobroncoscopio convencional de luz blanca tipo Olympus, FB160, aunque diversos estudios han mostrado una mayor eficacia del fibrobroncoscopio de fluorescencia en la detección de lesiones preneoplásicas y neoplasias sincrónicas $(6,7)$.

Actualmente, la fibrobroncoscopia y el TAC facilitan el diagnostico precoz de NPMP frente a los estudios quirúrgicos y sobre necropsias con los que se llegaba al diagnostico hace años. Esto nos ofrece la oportunidad de permanecer atentos ante la posibilidad de aumentar en el índice de NPMP detectadas, cuyas referencias siguen siendo aun hoy escasas en la literatura.

J. I. Ramos-Clemente Romero, M. A. Pérez Ramos, A. Benavente Fernández, M. J. Romero Jiménez, R. Martínez García, A. Barrios Merino

\section{Servicios de Medicina Interna y Anatomía Patológica. Hospital Infanta Elena. Huelva}

1. Rosengart TK, Martín N, Ghosn P, Buró M. Multiple primary lung carcinomas: prognosis and treatment. Ann Thorac Surg 1991; 52: 773-779.

2. Martíni N, Malamed MR. Multiple prymary lung cancers. J Thorac Cardiovasc Sung 1975; 70: 606-612.

3. Travis WD, Brambilla E, Muller-Hermelink HK, Harris CC (Eds.): World Health Organization Classification of Tumours. Patology and Genetics of Tumours of the Lung, Pleura, Thymus and Heart. IARC Press: Lyon 2004

4. Abbey Smith R. Evaluation of the long-term results of sugery from bronquial carcinoma. J Thorac Cardiovasc Surg 1981; 82: 325-333.

5. Grupo de Trabajo de la SEPAR. Normativa actualizada (1998) sobre diagnóstico y estadificación del carcinoma broncogénico. Arch Bronconeumol 1998; 34: 437-52.

6. Pasic A, Vonk-Noordegraaf A, Risse EK, Postus PE, Sutedja TG. Multiple suspicious lesions detected by autofluorescence bronchoscopy predict malignant development in the bronchial mucosa in high risk patients. Lung Cancer 2003; 41: 295-301.

7. Sutedja TG, Venmans BJ, Smit EP, Postmus PE. Fluorescence boncoschopy for early detection of lung cancer: a clinical perspective. Lung Cancer 2001; 34: 157-68.

\section{Bacteriemia por Serratia marcescens en paciente con colelitiasis}

\section{Sr. Director:}

Serratia marcescens es un bacilo gramnegativo que produce infecciones en pacientes con inmunidad disminuida bien por enfermedades sistémicas o por tratamientos médicos inmunosupresores. Describimos aquí un caso excepcional de infección extrahospitalaria en un paciente sin ninguna patología de base.

Se trata de un paciente sin antecedentes médicos ni epidemiológicos de interés que estando previamente bien presenta 3 semanas antes de su ingreso fiebre de $38-39{ }^{\circ} \mathrm{C}$ con eventuales escalofríos y tiritona así como malestar general sin otra sintomatología asociada. El cuadro clínico se prolonga durante 3-4 días desapareciendo con antitérmicos y tratamiento con un antibiótico intramuscular que el paciente no puede precisar. Cinco días después reaparece la fiebre con iguales características por lo que recibe tratamiento con claritromicina y vuelve a desaparecer la fiebre durante una semana hasta que la noche de su ingreso presenta de nuevo fiebre de alto grado. En ningún momento presenta dolor abdominal ni otra focalidad clínica. En la exploración física inicial no se aprecian alteraciones a excepción de una temperatura de $39^{\circ} \mathrm{C}$. En el hemograma presentaba 15.000 leucocitos con un $84 \%$ de neutrófilos sin otras alteraciones; en la bioquímica destacaba una bilirrubina total de 1,5 con el resto de parámetros dentro de la normalidad; el sedimento de orina y la radiografía de tórax no mostraban alteraciones.

Se obtuvieron 4 hemocultivos que resultaron positivos para Serratia marcescens sensible a piperacilina-tazobactan, cefotaxima, ceftacidima, cefepime, aztreonam, tobramicina, ciprofloxacino y cotrimoxazol. Un ecocardiograma transtorácico y transesofágico no mostró alteraciones. En la ecografía abdominal se evidenció colelitiasis (Fig. 1) que se confirmaba en un TAC toraco-abdominal. A los 10 días de su ingreso y mientras recibía tratamiento con piperacilina-tazobactan (al que inicialmente se asoció amikacina) presenta clínica compatible con cólico biliar (dolor en hipocondrio derecho y náuseas) y en las pruebas complementarias se confirma discreto aumento de amilasa y lipasa en plasma llegando a alcanzar cifras de bilirrubina total de $6,5 \mathrm{mg} / \mathrm{dl}$ (bilirrubina directa de $5,4 \mathrm{mg} / \mathrm{dl}$ ). La ecografía de control no mostró complicaciones en vía biliar y el curso clínico fue adecuado con medidas médicas. Se consultó el caso con el Servicio de Cirugía y se realizó colecistectomía laparoscópica una vez resuelto el cuadro de pancreatitis aguda. El postoperatorio cursó sin incidencias y el paciente permaneció afebril desde las 48 horas tras el tratamiento antibiótico. A pesar de lo atípico del caso y de la ausencia de síntomas abdominales iniciales a excepción del hallazgo ecográfico de colelitiasis el cuadro clínico se interpretó como síndrome febril en relación con bacteriemia por $S$. marcescens de probable origen biliar en un paciente con coledocolitiasis.

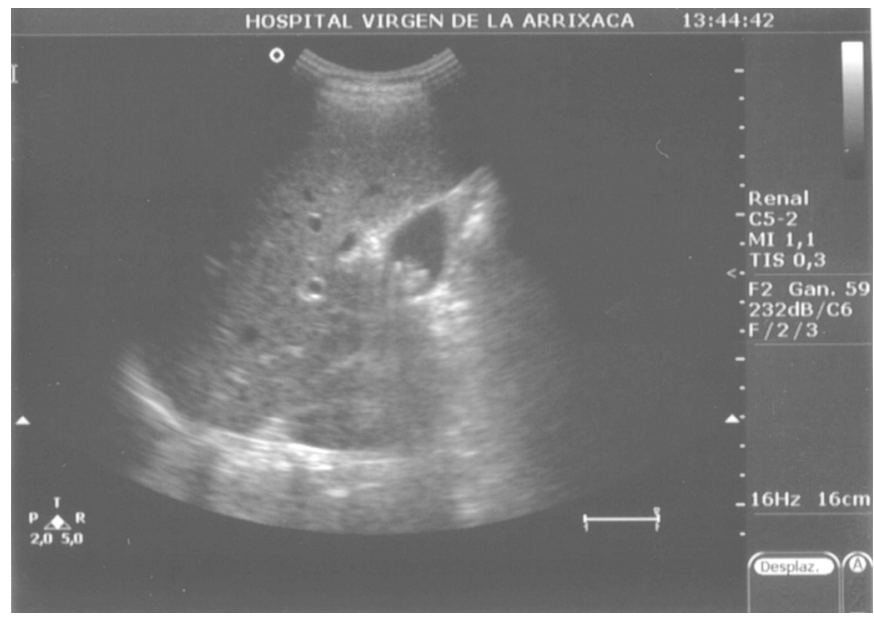

Fig. 1. Imagen de coledocolitiasis en ecografía abdominal.

El género Serratia, considerado desde su descubrimiento en 1823 por Bizio como un saprófito banal se ha convertido en la actualidad en una cepa endémica en muchos hospitales produ- 